\title{
A "videocracia" e a caricatura como recurso imagético
}

Vinícius Guimarães Dias Francisco ${ }^{7}$

DOI 10.20396/eha.vil4.3357

Introdução

\author{
Solamente el hombre rie \\ y ningún otro animal, \\ él solo ríe, y ninguno \\ tiene más de que llorar. ${ }^{2}$
}

A pesquisa se debruçou, a princípio, sobre bibliografia pertencente a diferentes acervos da biblioteca da Universidade Federal de Minas Gerais (UFMC), como A História da Caricatura no Brasil, de Herman Lima, e que, por sua vez, lançam luz sobre diferentes arquivos e coleções, dentre os quais os volumes de periódicos ilustrados contidos na Biblioteca Nacional. A exploração se volta a diferentes visões temporais - como o da caricatura no período monárquico, no emergir do projeto republicano e nos anos de ouro da charge, no retratar e no colecionismo do Barão do Rio Branco, e por fim, na campanha de tom jocoso que envolvem presidentes da redemocratização, como Itamar Franco e Dilma Rousseff, colhendo de distintas fontes - a fim de caracterizar um aporte que nos possibilite analisar os possíveis progressos do artifício da caricatura na contemporaneidade, quando empregada enquanto recurso satírico, sobretudo na charge e no acompanhamento a chistes.

À parte da caracterização deste amplo contexto, introduz-se aqui o problema central no presente artigo, que por sua vez atende à provocação proposta no XIV Encontro de História da Arte: Histórias do ol har. Pois, ao se propor um olhar sobre a evolução do emprego da caricatura, considerase que está contemplado parte do desafio de lidarmos, como coloca a apresentação do evento, com o protagonismo do olhar, em companhia dos crescentes produção e profusão de imagens.

Afinal, diante do ambiente virtual e das novas tecnologias da imagem e da comunicação, da

\footnotetext{
1 Vinícius Guimarães Dias Francisco está, atualmente, no sétimo período em Artes Visuais pela Universidade Federal de Minas Gerais, em que cursa a habilitação em Desenho.

2 Versos de autoria de Francisco de La Torre, disponíveis no prefácio de Sergio Fernández em: RAMÍREZ, Manuel González. La caricatura politica, Fuentes para la Historia de la Revolución Mexicana v. II. México: Fondo de Cultura Económica, $1^{\mathrm{a}}$ edição, 1955, p. 7.
} 
sua fluidez e da perseverança de visões-de-mundo já arraigadas na sociedade, bem como em tempos de um debate público intenso, retórico, polarizado - que frequentemente tende, por si próprio, a beirar o ridículo - e que envolve pilares como a imprensa, refletir sobre o riso, sobre tal recurso imagético, a política e sobre a esfera coletiva se torna essencial. Aqui, entende-se a caricatura como um mecanismo imagético do desenho que, entre estereótipos, hipérboles e subversões, busca o humor visual, em linguagem plástica sintética e contextual. E que, quando empregada, reflete atributos, a respeito de diferentes intenções, interesses e contextos, como sobre costumes, política, gostos.

Ainda, busca-se tal reflexão a fim de exemplificar a forma como as novas formas de produção e circulação da imagem e do texto podem ter afetado a criação e a profusão do caricato: tanto para o artista visual, enquanto criador, quanto para o universo institucional da arte. Decerto, o satírico está presente na história da arte, e o caricato como recurso artístico não é inovador: temos, entretanto, novas perspectivas de colecionismo e consumo de imagens desde as novas tecnologias de reprodutibilidade técnica, das inovações técnicas na gravura, durante os séculos passados, na sociedade ocidental. A ilustrar uma evolução: do alcance ampliado pelas crescentes tiragens, perpassando pelos jornais e revistas de circulação nacional da segunda metade do século XX, para por fim chegar à contemporaneidade e o ambiente virtual.

\section{Desenvolvimento}

Cibernética que, em crescente importância para os mais diversos campos da informação, oferece, portanto, um novo desafio interpretativo também para as narrativas que teorizam a respeito das imagens: a mesma induz, como já afirmado, a novos formatos e a novas dinâmicas de produção, circulação e apreciação, sobretudo com os smartphones e as redes sociais. Há quem aposte inclusive no predomínio da visualidade sobre o texto escrito nos dias de hoje, e o termo videocracia, entre aspas já ao título, remete a este contexto, de forma ampla, mas também a uma das tratativas que já abordaram, a alguns anos, a proeminência da imagem virtual - que veio por parte de Giovanni Sartori com o livro Homo videns: Televisão e Pós-pensamento. Trata-se de apontar esta relação e discutir sua genuinidade, por uma estratégia que abarque a amplitude do mundo das imagens caricatas e seu desempenho na cultura.

Estabelece-se assim a necessidade de se contruir uma abordagem metodológica, portadora de conceitos de aplicação adequada ao objeto a ser analisado - a caricatura e a sua evolução, possibilitando a construção de uma relação entre este recurso plástico e as novas dinâmicas da imagem. 
Poderia-se deduzir sobre a temática a partir das motivações filosóficas que estão por trás do riso, incluindo aí a caricatura e o texto, e gêneros como a charge, ou induzir uma provocação a respeito da história destas imagens.

Começando pela primeira dessas alternativas, e partindo de uma referência já citada como fonte destas reflexões; afinal, o texto Homo videns contém um conceito adequado para se pensar a nova forma de ver tais imagens? Decerto o comentário de Giovanni Sartori não passa despercebido como uma oportunidade de se comentar a crescente primazia das imagens na cultura, sobretudo considerando que o mesmo é bem claro e sintético em demonstrar suas intenções argumentativas. E, entretanto, adentrar nos méritos e deméritos do ensaio de Sartori não nos levaria a conclusões: não é o caso, por ora, de se discutir a respeito da denúncia do autor sobre os impactos deste giro do escrito para a imagem, sobre a capacidade de compreensão e abstração do ocidental ao longo da história.

Se se persistisse neste caminho, chegar-se-ia em seguida a uma investigação sobre a persistência deste recurso - a caricatura - no ambiente virtual, e a uma reflexão sobre o Porquê rimos? Terry Eagleton, por exemplo, teoriza profundamente sobre o sentido do riso e do cômico na literatura33; há teóricos que definem a caricatura e a hipérbole, como é o caso do estruturalista Vladimir Propp, em Comicidade e Riso. Seria possível, ainda, recorrer a bibliográfica ainda mais específica, como IMPRENSA, HUMOR E CARICATURA-A questão dos estereótipos culturais, que por sua vez traz, em sua totalidade, importantes questões sobre este universo. Ricky Goodwin, por exemplo, aborda um interessante contrassenso, de que "existe em estereótipo a respeito dos estereótipos, o de que tenham um caráter pejorativo, sendo, portanto, prejudiciais" ${ }^{4}$, e, seria possível questionar se o riso continua a ser subversivo, filosoficamente radical, ou se nos tornamos ridículos com o cinismo de seus ensaios agressivos, na internet. Ainda, Herman de Lima e outros materiais complementares de História e arquivos poderiam auxiliar na construção de uma reflexão sobre a acidez da caricatura hoje. São ricas considerações que poderiam render portentosos silogismos ao raciocínio.

E, entretanto, o livro Itamar na Veja: análise do discurso jocoso chama a atenção, citando Propp e

\footnotetext{
3 Dando continuidade a uma tradição de pensadores, como colocado no prefácio de Imprensa, humor e caricatura: "A definição do cômico na Poética de Aristóteles como 'defeito ou torpeza que não causa dor nem destruição' foi uma das definições mais repetidas e reapropriadas na história das teorias sobre o riso"; são citados, em seguida, teóricos como o médico Laurent Joubert, do século XVI, estudiosos moralistas dos séculos XVII e XVIII - que colocam o humor não no defeito, mas no "contraste e na incongruência", sendo os limites do riso "dados pelo senso moral"-, chegando aos séculos XIX e XX, em que intelectuais como Bataille passam a comentar o riso como categoria filosófica e a respeito do "antirriso", ou riso destruidor, que segundo a autora do mesmo prefácio, não tem espaço na imprensa. Imprensa, humor e caricatura: a questão dos estereótipos culturais. Organização de Isabel Lustosa. - Belo Horizonte, editora UFMG, 2011, p. 16-17.

4 "Mas para o Humor estereótipos são ferramentas essenciais." COODWIN, Ricky. Imprensa, humor e caricatura: a questão dos estereótipos culturais. Organização de Isabel Lustosa. - Belo Horizonte, editora UFMG, 2011, p. 535.
} 
Bergson, para a necessidade de se atentar à especificidade da argumentação pretendida:

Propp adverte que a base para se elaborar um estudo sobre o cômico deve ser imbuída de espírito sério. Os fatos devem ser analisados com imparcialidade mesmo que convidem a suposições, a elucidações abstratas. Bergson (2001) recomenda que o pesquisador deve, ao se deparar com fatos ou expressões que provoquem o riso, observar a questão do caráter específico ou não específico do objeto, e dos fatos causadores. ${ }^{5}$

Portanto, o caso não é em si o humor dos exemplos de caricato a que podemos recorrer na reflexão, mas sim o produto que emprega este recurso em sua relação para com o ambiente virtual, dentre chistes em redes sociais como o Twitter, ou bem em charges e tirinhas de cartunistas hoje consagrados, em veículos de imprensa.

Passamos, por conseguinte, à segunda alternativa, prosseguindo para um raciocínio a partir de argumentos indutivos, que possam apontar elementos de possíveis modificações. Assim, construindo uma articulação sobre a caricatura na era do virtual, tem-se organizado em itens:

\section{1) $\mathrm{O}$ suporte}

A caricatura surge como recurso primeiro no desenho, e ganha espaço como múltiplo com as inovações da reprodutibilidade técnica, como frisa Herman de Lima: "Lançada a voga das sátiras de Daumier, na França, em 1831, em pranchas sôltas e, principalmente, através das revistas de Philippon, o Brasil não tardou em segui-la, porquanto seis anos depois apareciam entre nós as primeiras estampas dessa espécie." 0 notável suporte de produção e veiculação de gêneros como a charge, que empregam o caricato, são as páginas de jornais e revistas:

No começo do século XX, a caricatura é considerada a grande arte brasileira. Na efervescência da Belle Époque, multiplicam-se as publicações dedicadas ao gênero e consagramse muitos artistas. A Tagarela, Fon-Fon, O Malho, e Careta, só para citar algumas, são revistas que surgem neste período e revolucionam a imprensa ilustrada, com a predominância da cor e de um novo formato, tudo em papel de melhor qualidade. Nelas, o desenho de humor ganha cada vez mais espaço e o desenhista ocupa lugar privilegiado com suas charges publicadas nas capas. Em suas páginas, destacam-se os traços de Raul, K Lixto e J. Carlos, denominados "trio de ouro" [...].7

5 QUADROS, Aurora Cardoso de. Itamar na Veja: análise do discurso jocoso. Belo Horizonte: Cuatiara, 2002, p. 57.

6 LIMA, Herman. História da Caricatura no Brasil. Rio de Janeiro: editora José Olympio, $1^{\text {a }}$ edição, 1963, v. 1, p. 171.

7 O Barão do Rio Branco e a Caricatura: Coleção e Memória. Organização de Ângela Porto. - Rio de Janeiro: Centro de História e Documentação Diplomática, 2012. p 26 coleção e memória 
A caricatura nunca esteve, porém, restrita e sujeita às condições da imprensa: Goodwin, por exemplo, afirma que a quantidade de profissionais do desenho aumentou, mas que os espaços de publicação regrediram, e que passaram a existir espaços alternativos, como o de quadrinhos independentes ${ }^{8}$. Hoje, o meio virtual carrega também muito do caricato: há uma facilidade em se apropriar, editar e compartilhar imagens como a de Ciro Gomes (fig. 1), e também há uma característica efemeridade que a acompanha.

2) Criação e radicalidade

Esta caricatura do presidenciável também poderia chamar a atenção para mais um item, a respeito da autoria das imagens: alteraram-se, com os meios digitais e audiovisuais, a forma de se criar caricaturas, do desenho, à cultura impressa e pôr fim ao digital, com a facilidade da fotografia? Os chistes da internet tornam a hipérbole caricatural produtos de autoria pouco clara? Se tratam de entretenimento de internet, como poderiam ser em jornal e revista, ou envolvem responsabilidades das quais não pode disfarçar a sensação de anonimato que a internet traz, já que, muitas das vezes, são agressivas? Há de se lembrar, também, que alguns nomes mantêm um status de profissionalidade enquanto chargistas, como Laerte.

Que por sua vez sofrem com a militância e o policiamento ideológicos, com os confrontos de um campo político polarizado. Coloca-se assim um princípio conflituoso no que cerca este ato de criação, e que aponta justamente para o seu humor contextual; o ambiente virtual pode parecer acirrar e entregar muitas das facetas destas contradições, e, no entanto, não são novos a dubiedade e os conflitos que podem envolver as circunstâncias específicas de uma caricatura. O preço que se paga é uma desconfiança em relação a esta ferramenta de humor, que não vêm da internet: "El arte subalterno de la caricatura carga a cuestas su bastardia" 9 .

3) A profusão das imagens

Chama mais a atenção, neste item, o alcance que tais imagens possuem em nossa cultura,

\footnotetext{
8 COODWIN, Ricky. Imprensa, humor e caricatura: a questão dos estereótipos culturais. Organização de Isabel Lustosa. - Belo Horizonte, editora UFMG, 2011, p. 539-540.

9 RAMÍREZ, Manuel Conzález. La caricatura politica, Fuentes para la Historia de la Revolución Mexicana v. II. México, Fondo de Cultura Económica, $1^{a}$ edição, 1955, p. 23.
} 


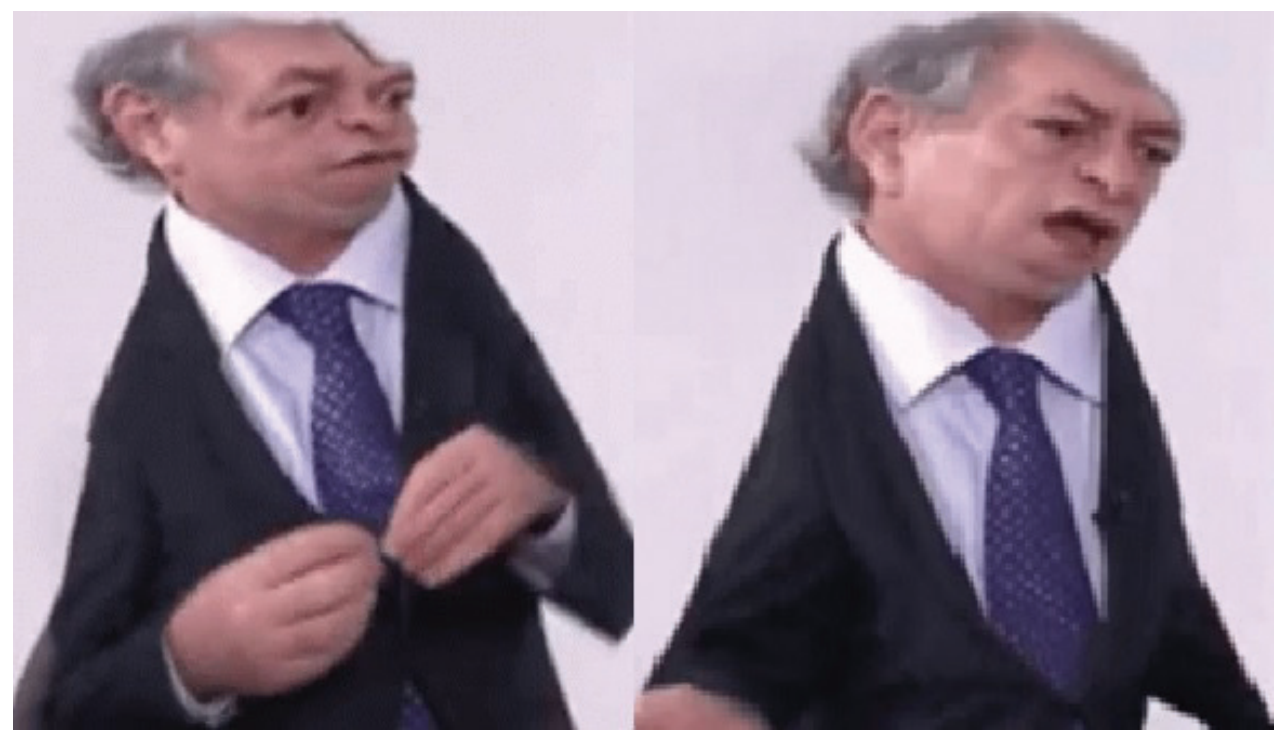

[Figura 1] Capturas de tela de um popular gif de Ciro Gomes.

sobretudo quando se trata de uma possível intensificação e de seu alcance por meio da internet.

Se já houveram caricaturistas de rua e de salões, bem como notáveis nomes da História da arte empregaram a caricatura, podemos ver hoje nomes que, dedicados quase integralmente a gêneros como a charge e as tirinhas, também portanto lançando mão do caricato, frequentando feiras e realizando exposições, e Coodwin já nos chamou a atenção para a fluidez destes espaços que os artistas da caricatura buscam ocupar. Um exemplo é André Dahmer, autor da série Malvados.

O mesmo Dahmer que veicula tirinhas de sua autoria em suas próprias redes sociais, de forma aberta - basta acessar uma de suas páginas pessoais; ele está também em veículos de imprensa, como a Folha de São Paulo, mas chama a atenção que comercialize livros compilando sua produção, produtos estampados e originais ou gravuras de seus desenhos em seu website. É possível ver suas obras no Google, expostas em uma parede, em galerias que realizam individuais do artista, ou ainda impressas no jornal, o que logo revela um poder de alcance.

Vale lembrar que este colecionismo não é inédito, são diversos os acervos históricos, e há figura que tenha colecionado a própria imagem na imprensa, como Maluf e o Barão do Rio Branco:

Durante o período em que foi Ministro das Relações Exteriores, Rio Branco coletou uma série de caricaturas, saídas na imprensa da Capital Federal, especialmente aquelas que se referiam a seus feitos na diplomacia. [...] A coleção de caricaturas do Barão do Rio Branco cobre, portanto, o período de 1902 a 1912 e contempla os grandes temas que frequentaram a imprensa na época. ${ }^{10}$

10 O Barão do Rio Branco e a Caricatura: Coleção e Memória. Organização de Ângela Porto. - Rio de Janeiro: Centro de História e Documen- 
4) A caricatura política

A tradição do gênero charge no Brasil está intrinsecamente ligada à caricatura e ao humor político, bem como ocorre com cartuns, tirinhas; assim permanecem unidos o caricato e o riso nos tempos de redes sociais, sendo este espaço um local em que muitas vezes se excedem os limites do bom senso e do ridículo.

É possível citar uma série de publicações que chamam a atenção para esta histórica relação, e de forma recente, pós redemocratização, cito como exemplos dois compilados: Fora Collor: o fenômeno em decomposição, de desenhos de Chico Caruso, e 100 charges da era Itamar, com charges de Clauco e Angeli, publicados respectivamente pelos grupos Clobo e Folha de São Paulo.

O tom jocoso se mantém também nas publicações online, ganhando força como no que se refere à política. Não é distante a campanha agressiva que sofreu Dilma Rousseff, com caricaturas irônicas, difamatórias e machistas, nem tampouco incomum seria citar os contornos caricatos que passam a cercar a imagem do atual presidente.

\section{Conclusão}

Afinal, há uma evolução do caricato? Construída uma ambiência da caricatura nos exemplos acima, parece cabível a afirmação de que a esfera do virtual/cibernético de fato intensificou a relação entre a cultura ocidental e o seu rol, o seu mundo de imagens. Oferta-se, com os smartphones em mãos e com os olhos voltados às plataformas socias, um amplo alcance das imagens, e a dinâmica dos gêneros textuais que empregam a caricatura se adequaram às novas possibilidades, não se limitando hoje a um entendimento de que pertencem necessariamente ao âmbito dos impressos.

Seria destacável, claro, pontuar que o presente raciocínio não pode desconsiderar a marginalidade imposta, insistindo na desigualdade no acesso às tecnologias; permanece, também, uma possível consideração sobre a estetização do mundo e de suas imediações.

tação Diplomática, 2012. P. 15 coleção e memória 


\section{Referências Bibliográficas}

CARUSO, Chico. Fora Collor: o fenômeno em decomposição. São Paulo: Clobo, 1992.

LIMA, Herman. História da Caricatura no Brasil. Rio de Janeiro: editora José Olympio, $1^{\text {a }}$ edição, 1963.

LUSTOSA, Isabel. Imprensa, humor e caricatura: a questão dos estereótipos culturais. Organização de Isabel Lustosa. - Belo Horizonte: editora UFMG, 2011.

QUADROS, Aurora Cardoso de. Itamar na Veja: análise do discurso jocoso. Belo Horizonte: Cuatiara, 2002.

RAMÍREZ, Manuel González. La caricatura politica, Fuentes para la Historia de la Revolución Mexicana v. II. México: Fondo de Cultura Económica, $1^{\text {a }}$ edição, 1955.

. O Barão do Rio Branco e a Caricatura: Coleção e Memória. Organização de Ângela Porto. - Rio de Janeiro: Centro de História e Documentação Diplomática, 2012. 100 charges da era Itamar / [charges de] Glauco, Angeli. São Paulo: Folha de São Paulo, 1993. 